\title{
ANALISIS KEBUTUHAN PELATIHAN PEJABAT STRUKTURAL BERDASARKAN TRAINING NEED ASESSMENT DI RSUD dr. R SOEDARSONO KOTA PASURUAN
}

\author{
Ema Novita Ristya Putri, Karjono* \\ *Prodi Administrasi Rumah Sakit STIKES Yayasan RS. Dr. Soetomo, \\ Jl. Karangmenjangan 12 Surabaya \\ Email : ema201212017@gmail.com
}

\begin{abstract}
ABSTRAK
Penilaian kebutuhan pelatihan adalah suatu proses kegiatan yang bertujuan untuk mengidentifikasi kesenjangan kinerja yang disebabkan oleh kekurangan pengetahuan, ketrampilan, dan sikap kerja. Penilaian kebutuhan pelatihan terdiri dari tiga tingkatan analisis yaitu organisasi, individu dan tugas. Tujuan dari penelitian ini adalah untuk menganalisis kebutuhan pelatihan pejabat struktural di RSUD dr.Soedarsono berdasarkan hasil penilaian kebutuhan (Training Needs Assessment). Penelitian ini adalah penelitian deskriptif, teknik pengumpulan data dilakukan melalui kuesioner. Subyek penelitian ini adalah para pejabat struktural mulai dari kepala bagian, kepala bidang dan para kepala seksi dan kepala sub bagian.Berdasarkan hasil penelitian, sistem pengembangan karier masih rendah yaitu 49,2\%. Penentuan kebutuhan pelatihan diperoleh dari usulan tiap pejabat dan kesenjangan antara pelatihan yang pernah diikuti dengan PMK nomor 971/2009. Prioritas 1 pelatihan yang secara organisasi dibutuhkan, dan individu mengusulkan. Prioritas 2 pelatihan yang secara individu mengusulkan, secara organisasi tidak membutuhkan. Prioritas 3 pelatihan yang secara organisasi membutuhkan, individu tidak mengusulkan. Pelatihan yang dibutuhkan antara lain kewirausahaan, rencana implementasi dan rencana tahunan, rencana aksi strategis, sistem rekrutmen pegawai, sistem remunerasi dan kepemimpinan. Berdasarkan pembahasan yang telah dilakukan terhadap analisa kebutuhan pelatihan dan sistem pengembangan karier untuk pejabat struktural di RSUD dr. R Soedarsono dapat disimpulkan sistem pengembangan karier dilihat dari hasil IKK masih rendah dan Analisa kebutuhan pelatihan pejabat struktural berdasarkan training need assesment dengan analisa organisasi dan analisa individu masih kurang memadai.
\end{abstract}

Kata Kunci : Penilaian Kebutuhan Pelatihan, Pejabat Struktural, Sistem Pengembangan Karier.

\section{ABSTRACT}

The needs of training's assessment is a process of training activities aimed at identifying gaps in performance caused by lack of knowledge, skills, and work ethic. Training needs assessment consists of three levels of analysis, organizations, individuals and tasks. The purpose of this study is to analyze the training needs of structural officer in $d r$.Soedarsono hospital based on the needs assessment (Training needs assessment). This research is descriptive research, data collection techniques through a questionnaire. The subjects of this study is the structural officials from the head of division and the head section and the head of the subdivisions.Based on the results of research, career development system is still low, that is $49.2 \%$. Determination of training requirements obtained from officials of each proposal and the gap between the training which have been followed by the PMK number 971/2009. Priority 1 is the organization of training required, and the individual 
proposed. Priority 2 training individually propose, as an organization does not need. Priority 3 training which requires organizations, individuals do not propose. Training needed includes entrepreneurship, implementation plans and annual plans, strategic action plans, recruitment system, remuneration system and leadership. Based on the discussion that has been conducted on the analysis of training needs and career development system for structural officer $d r$. R Sudarsono concluded the career development system is seen from the IKK is still low and the analysis of training needs structural officials based training needs assessment with organizational analysis and individual analysis are still inadequate.

Keywords: Training Need Assesment, Structural Officers, Career Development System.

\section{PENDAHULUAN}

Era globalisasi saat ini, kebutuhan akan peningkatan penguasaan ilmu dan teknologi semakin dirasakan seiring dengan pola hubungan yang bersifat rasional. Seluruh bidang produksi dan jasa memiliki kebutuhan akan peningkatan penguasaan ilmu dan teknologi dalam menghadapi persaingan tingkat global. Ketersediaan sumber daya manusia sangat menentukan keberhasilan organisasi. Sumber daya manusia tidak lagi dipandang sebagai biaya (beban) tetapi sebagai investasi jangka panjang. Dapat dipastikan tujuan organisasi dapat terwujud meliputi keberlangsungan organisasi, pertumbuhan dan kesejahteraan dapat tercapai.

Rumah sakit merupakan organisasi penyelenggara pelayanan kesehatan bersifat komplek, dinamis, dan digerakkan oleh sumber daya manusia dari berbagai profesi. Rumah sakit dalam menghadapi masyarakat ekonomi ASEAN (MEA) membutuhkan sumber daya manusia yang adaptif, senantiasa meningkatkan kemampuannya serta memiliki kemampuan komunikasi, penguasaan informasi, dan teknologi kesehatan terkini.

Rumah sakit seharusnya memiliki sistem pengembangan karier bagi semua jenis tenaga kesehatan termasuk pejabat struktural. Untuk pengembangan karier setiap individu membutuhkan jenis-jenis pelatihan sesuai dengan jenjangnya. Dalam menjalankan fungsi rumah sakit meliputi pelayanan, pendidikan, dan penelitian. Semua sumber daya manusia harus memiliki kesamaan persepsi dan pemahaman terhadap visi misi dan tujuan bersama yang telah ditetapkan dalam perencanaan strategis.

Pelatihan merupakan proses untuk membentuk sikap dan karakter serta membekali karyawan dibidang teknis dan fungsi dengan memberikan pengetahuan, ketrampilan dan sikap sesuai dengan jenis tenaganya. Pelatihan mengacu pada hasil kajian kebutuhan pelatihan dalam melaksanakan fungsi dan teknis sesuai tugas pokok dan fungsinya masing-masing jenis tanaga. Kajian kebutuhan pelatihan juga dibutuhkan untuk para pejabat 
struktural dalam menjalankan tugas pokok dan fungsinya.

Training Need Assesment (TNA) atau kajian kebutuhan pelatihan bagi pejabat struktural merupakan dokumen awal untuk mengidentifikasi kebutuhan pelatihan dibidang manajemen dan kepemimpinn di RSUD dr. R Soedarsono. TNA juga digunakan sebagai bahan penyusunan kurikulum dan silabus masing-masing jenis pelatihan.

Berdasarkan pengalaman magang diperoleh gambaran bahwa di RSUD dr. R Soedarsono belum memiliki dokumen kajian TNA pada semua jenis tenaga serta jenis pelatihan yang diikuti belum sesuai dengan standar PMK nomor 971 tahun 2009.

Berdasarkan latar belakang tersebut maka masalah yang diangkat dalam penelitian ini adalah ketidaksesuaian pelatihan pejabat struktural yang diikuti berdasarkan PMK nomor 971 tahun 2009 di RSUD dr.R Soedarsono Kota Pasuruan.

\section{METODE PENELITIAN}

Penelitian ini dilakukan di RSUD dr.R Sedarsono Kota Pasuruan pada bulan Juni tahun 2016, dengan kelompok sasaran pejabat struktural eselon tiga dan empat.

Subyek penelitian ini melibatkan para pejabat struktural mulai dari kepala bagian, bidang, para kepala seksi dan kepala sub bagian yangbekerja di RSUD dr. R Soedarsono, yang berjumlah 13 orang, yang selanjutnya disebut pejabat struktural. Instrumen penelitian ini menggunakan kuesioner.

\section{Hasil Penelitian dan Pembahasan}

Hasil Penelitian

\section{Gambaran Umum Lokasi Penelitian}

RSUD dr. R. Soedarsono adalah Instansi Pemerintah yang mempunyai tugas melaksanakan pelayanan kesehatan paripurna, pendidikan dan pelatihan, penelitian dan pengembangan penapisan teknologi bidang kesehatan. RSUD dr.R.Soedarsono merupakan satu - satunya rumah sakit milik pemerintah daerah Kota Pasuruan, yang didalam pelaksanaannya dipimpin oleh seorang Direktur dan didukung oleh tenaga fungsional dibidang pelayanan dan tenaga struktural dibidang manajerial.

Lokasi RSUD dr. R. Soedarsono sangat strategis yaitu berada pada poros jalan utama Banyuwangi - Surabaya. Rumah sakit ini merupakan rumah sakit umum kelas $\mathrm{C}$.

\section{Hasil Analisis Individu}

Pejabat struktural yang memiliki masa kerja 1 tahun sebanyak 46\%, masa kerja lebih dari satu tahun 53\%. Lima pejabat struktural belum memiliki pengalaman jabatan, 7 pejabat sudah memiliki pengalaman menduduki jabatan struktural.

1 dari 13 pejabat struktural masih belum mengikuti diklat kepemimpinan. 13 
pejabat struktural sudah melakukan diklat fungsional sesuai dengan tugas pokok dan fungsinya. Sedangkan untuk diklat teknis dari 13 pejabat struktural masih belum mengikuti diklat tersebut. Terdapat kesenjangan jenis pelatihan yang pernah diikuti berdasarkan PMK nomor 971/2009. Seperti pada tabel 1 dibawah ini.

Tabel 1. Hasil Karakteristik Responden Berdasarkan Jenis Pelatihan Yang Pernah Diikuti Sesuai PMK Nomor 971/2009

\begin{tabular}{|c|c|c|c|c|c|c|c|c|c|}
\hline \multirow[t]{2}{*}{ No } & \multirow[t]{2}{*}{ Jabatan } & \multicolumn{6}{|c|}{$\begin{array}{c}\text { Jenis Diklat Sesuai PMK Nomor } \\
971 / 2009\end{array}$} & \multirow[t]{2}{*}{ Pelaksanaan } & \multirow[t]{2}{*}{ Kesenjangan } \\
\hline & & 1 & 2 & 3 & 4 & 5 & 6 & & \\
\hline \multicolumn{10}{|c|}{ Eselon III } \\
\hline 1. & 002 & 0 & 0 & 0 & 0 & 0 & 0 & 0 & 6 \\
\hline 2. & 003 & 2 & 1 & 2 & 2 & 0 & 0 & 7 & 2 \\
\hline 3. & 004 & 2 & 0 & 0 & 0 & 0 & 0 & 2 & 5 \\
\hline 4. & 005 & 2 & 0 & 0 & 0 & 0 & 0 & 2 & 5 \\
\hline \multicolumn{2}{|c|}{ Jumlah } & 6 & 1 & 2 & 2 & 0 & 0 & 11 & 2 \\
\hline \multicolumn{10}{|c|}{ Eselon IV } \\
\hline 5. & 022 & 1 & 0 & 0 & 0 & 0 & 0 & 1 & 5 \\
\hline 6. & 021 & 1 & 0 & 0 & 0 & 0 & 0 & 1 & 5 \\
\hline 7. & 032 & 1 & 0 & 0 & 0 & 0 & 0 & 1 & 5 \\
\hline 8. & 031 & 1 & 0 & 0 & 0 & 1 & 0 & 2 & 4 \\
\hline 9. & 041 & 1 & 0 & 0 & 0 & 1 & 0 & 2 & 4 \\
\hline 10. & 042 & 1 & 0 & 0 & 0 & 0 & 0 & 1 & 5 \\
\hline 11. & 053 & 1 & 0 & 1 & 0 & 0 & 0 & 2 & 4 \\
\hline 12. & 051 & 1 & 0 & 0 & 0 & 0 & 0 & 1 & 5 \\
\hline 13. & 052 & 1 & 0 & 0 & 0 & 0 & 0 & 1 & 5 \\
\hline \multicolumn{2}{|c|}{ Jumlah } & 9 & 0 & 1 & 0 & 2 & 0 & 12 & 62 \\
\hline
\end{tabular}

*Keterangan : 1 kepemimpinan, 2 kewirausahaan, 3 rencana aksi strategis,

4 rencana implementasi\&rencana tahunan, 5 sistem rekrutmen pegawai, sistem remunerasi

Sumber: Diolah Dari Hasil Kuesioner Juni 2016

Pejabat struktural masih belum berkompeten dalam menjalankan tugas pokok dan fungsinya. Indek kepuasan pejabat struktural berdasarkan penilaian/persepsi para pejabat masih rendah yaitu sebesar $49 \%$.

Jenis pelatihan yang dibutuhkan pejabat strukural meliputi sistem remunerasi $100 \%$, kewirausahaan $85,7 \%$, kepemimpinan $83,3 \%$, sistem rekrutmen pegawai $60 \%$, rencana implementasi \& rencana tahunan $42,8 \%$ dan rencana aksi strategis $36,3 \%$. Seperti pada tabel 2 dibawah ini. 
Tabel 2. Jenis Pelatihan Yang Dibutuhkan Oleh Pejabat Struktural Di RSUD dr. R Soedarsono

\begin{tabular}{|c|c|c|c|}
\hline No & Jenis Pelatihan Yang Dibutuhkan & $\begin{array}{c}\text { Jumlah Pejabat } \\
\text { Struktural Yang } \\
\text { Membutuhkan }\end{array}$ & $\begin{array}{c}\text { Presentase } \\
(\%)\end{array}$ \\
\hline \multirow{6}{*}{1.} & Kepemimpinan : & & \multirow{6}{*}{83,3} \\
\hline & a. Diklat PIM & 2 & \\
\hline & b. Kepemimpinan dalam organisasi & 1 & \\
\hline & c. Leadership entrepreneur & 1 & \\
\hline & d. Manajemen \& Kepemimpinan Rs & 1 & \\
\hline & e. Diklat PIM \& Motivasi & 1 & \\
\hline \multirow{7}{*}{2.} & Kewirusahaan : & & \multirow{7}{*}{85,7} \\
\hline & a. Marketing & 2 & \\
\hline & b. Entrepreneur & 1 & \\
\hline & c. Manajemen keuangan & 1 & \\
\hline & d. Kewirausahaan bagi RS & 1 & \\
\hline & e. Pengelolaan \& pengawasan BLUD & 1 & \\
\hline & f. Medical cost & 1 & \\
\hline \multirow{5}{*}{3.} & Rencana aksi strategis : & & \multirow{5}{*}{36,3} \\
\hline & a. $\mathrm{RSB}$ & 5 & \\
\hline & b. $\mathrm{RBA}$ & 3 & \\
\hline & c. RENSTRA Rs & 2 & \\
\hline & d. BSC & 1 & \\
\hline \multirow{4}{*}{4.} & Rencana implementasi \& rencana tahunan : & & \multirow{4}{*}{42,8} \\
\hline & a. Peenggearaan pelaksanaan perencanaan Rs & 4 & \\
\hline & b. Penyusunan laporan keuangan & 2 & \\
\hline & c. Penyusunan laporan kinerja & 1 & \\
\hline \multirow[t]{7}{*}{5.} & Sistem rekrutmen pegawai & & \multirow{7}{*}{60} \\
\hline & a. Penyusunan standart kebutuhan SDM & 3 & \\
\hline & b. Rekrutmen pegawai BLUD & 2 & \\
\hline & c. Penyusunan pemenuhan kebutuhan SDM Rs & 2 & \\
\hline & d. Tata kelola pegawai & 1 & \\
\hline & e. Pengembangan SDM & 1 & \\
\hline & f. $\quad$ Kredensialing & 1 & \\
\hline 6. & Sistem remunerasi & 10 & 100 \\
\hline
\end{tabular}

Sumber : Diolah Dari Hasil Kuesioner Juni 2016 


\section{Hasil Analisis Organisasi}

Eselon III dan eselon IV berjumlah 13 orang pejabat struktural yang direncanakan sebagai responden, keseluruhan berpartisipasi dalam mengisi kuesioner yang diberikn oleh peneliti.

Pengembangan karier pejabat struktural yang diperoleh berdasarkan kuesioner IKK masih rendah yaitu sebesar $49,2 \%$.
Jenis kebutuhan pelatihan tingkat organisasi didapat dari kesenjangan pelatihan yang pernah diikuti pejabat struktural dengan standar PMK nomor 971/2009, semua pejabat struktural membutuhkan pelatihan untuk melaksanakan tugas pokok dan fungsinya. Seperti pada tabel 3 dibawah ini.

Tabel 3. Jenis Kebutuhan Pelatihan Tingkat Organisasi

\begin{tabular}{|c|c|c|c|c|c|}
\hline & Bidang Pelayanan & $\begin{array}{c}\text { Bidang } \\
\text { Keperawatan }\end{array}$ & $\begin{array}{c}\text { Bidang } \\
\text { Pengembangan }\end{array}$ & Bagian TU & Jumlah \\
\hline Eselon III & $\begin{array}{l}\text { a. Kepemimpinan } \\
\text { b. Kewirausahaan } \\
\text { c. Rencana aksi } \\
\text { strategis } \\
\text { d. Rencana } \\
\text { implementasi\&r } \\
\text { encana tahuan } \\
\text { e. Sistem } \\
\text { rekrutmen } \\
\text { pegawai }\end{array}$ & $\begin{aligned} & \text { a. } \text { Sistem } \\
& \text { rekrutmen } \\
& \text { pegawai } \\
& \text { b. Sistem } \\
& \text { remunerasi }\end{aligned}$ & $\begin{array}{ll}\text { a. } & \text { Kewirausaha } \\
\text { an } \\
\text { b. Rencana aksi } \\
\text { strategis } \\
\text { c. Rencana } \\
\text { implementasi } \\
\text { \&rencana } \\
\text { tahunan } \\
\text { d. Sistem } \\
\text { rekrutmen } \\
\text { pegawai } \\
\text { e. Sistem } \\
\text { remunerasi }\end{array}$ & $\begin{array}{l}\text { a. Kewirausah } \\
\text { aan } \\
\text { b. Rencana } \\
\text { aksi strategis } \\
\text { c. Rencana } \\
\text { implementas } \\
\text { i\&rencana } \\
\text { tahunan } \\
\text { d. Sistem } \\
\text { rekrutmen } \\
\text { pegawai } \\
\text { e. Sistem } \\
\text { remunerasi } \\
\end{array}$ & \\
\hline Jumlah & 5 & 2 & 5 & 4 & 16 \\
\hline \multicolumn{6}{|l|}{ Eselon IV } \\
\hline 021 & $\begin{array}{l}\text { a. Kewirausahaa } \\
\mathrm{n} \\
\text { b. Rencana aksi } \\
\text { strategis } \\
\text { c. Rencana } \\
\text { implementasi } \\
\text { \&rencana } \\
\text { tahunan } \\
\text { d. Sistem } \\
\text { rekrutmen } \\
\text { pegawai } \\
\text { e. Sistem } \\
\text { remunerasi }\end{array}$ & $\begin{array}{l}\text { a. Kewirausaha } \\
\text { an } \\
\text { b. Rencana } \\
\text { aksi strategis } \\
\text { c. } \text { Sistem } \\
\text { rekrutmen } \\
\text { pegawai } \\
\text { d. Sistem } \\
\text { remunerasi }\end{array}$ & $\begin{array}{l}\text { a. Kewirausahaan } \\
\text { b. Rencana aksi } \\
\text { strategis } \\
\text { c. Sistem } \\
\text { rekrutmen } \\
\text { pegawai } \\
\text { d.Sistem } \\
\text { remunerasi }\end{array}$ & $\begin{array}{l}\text { a. Rencana aksi } \\
\text { strategis } \\
\text { b. Rencana } \\
\text { implementas } \\
\text { i\&rencana } \\
\text { tahunan } \\
\text { c. Sistem } \\
\text { rekrutmen } \\
\text { pegawai }\end{array}$ & \\
\hline 022 & $\begin{array}{l}\text { a. Kewirausahaan } \\
\text { b. Rencana aksi } \\
\text { strategis }\end{array}$ & $\begin{array}{l}\text { a. Kewirausaha } \\
\text { an } \\
\text { b. Rencana }\end{array}$ & $\begin{array}{l}\text { a. Kewirausaha } \\
\text { an } \\
\text { b. Rencana aksi }\end{array}$ & $\begin{array}{l}\text { a. Rencana aksi } \\
\text { startegis } \\
\text { b. Rencana }\end{array}$ & \\
\hline
\end{tabular}




\begin{tabular}{|c|c|c|c|c|c|}
\hline & Bidang Pelayanan & $\begin{array}{c}\text { Bidang } \\
\text { Keperawatan }\end{array}$ & $\begin{array}{c}\text { Bidang } \\
\text { Pengembangan }\end{array}$ & Bagian TU & Jumlah \\
\hline & 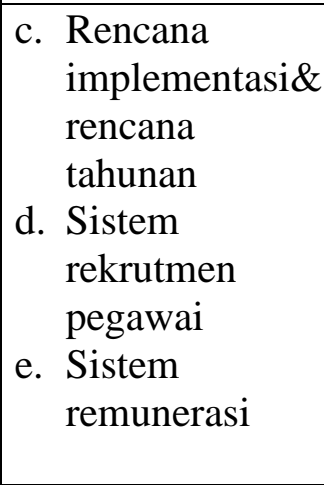 & $\begin{array}{l}\text { aksi strategi } \\
\text { c. Rencana } \\
\text { implementas } \\
\text { i\&rencana } \\
\text { tahuan } \\
\text { d. Sistem } \\
\text { rekrutmen } \\
\text { pegawai } \\
\text { e. Sistem } \\
\text { remunerasi }\end{array}$ & 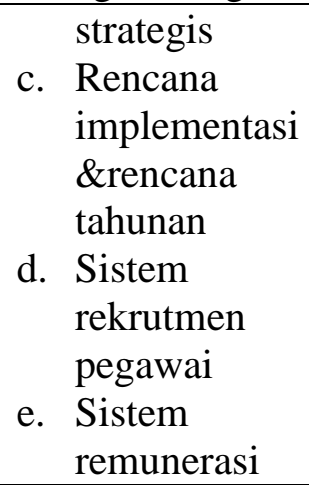 & $\begin{array}{l}\text { implementas } \\
\text { i\&rencana } \\
\text { tahunan }\end{array}$ & \\
\hline 023 & & & & \begin{tabular}{|l} 
a. \\
an \\
b. Rewirausaha \\
strategis \\
c. Rencana \\
implementas \\
i\&rencana \\
tahunan \\
d. Sistem \\
rekrutmen \\
pegawai \\
e. Sistem \\
remunerasi \\
\end{tabular} & \\
\hline Jumlah & 10 & 9 & 9 & 10 & 38 \\
\hline
\end{tabular}

Sumber : Dioalah Dari Hasil Kuesioner Juni 2016

\section{PEMBAHASAN}

\section{Analisis Individu}

Analisis individu dilaksanakan untuk mengidentifikasi tentang masa kerja, pengalaman jabatan, jenis pengalaman pelatihan, pelatihan yang pernah diikuti sesuai standar, mengetahui kompetensi, kepuasan kerja, serta jenis pelatihan apa yang diperlukan.

Analisis individu bertujuan untuk memeriksa seberapa baik individu karyawan dalam melaksanakan pekerjaannya, dengan melakukan analisis individu akan didadapatkan kebutuhan pelatihan yang diperlukan oleh karyawan sehingga dapat diupayakan program pelatihan yang dapat menanggulangi masalah tersebut.

Menurut PMK Nomor 971/2009 tentang standar kompetensi pejabat struktural kesehatan pasal 16 dan 17 dijelaskan bahwa kepala bidang, kepala bagian, kepala seksi, kepala subbagian telah mengikuti pelatihan kepemimpinan, kewirausahaan, rencana aksi strategis, rencana implementasi dan rencanatahunan, 
sistem rekrutmen pegawai, dan sistem remunerasi.

Pelatihan sebagaimana yang dimaksud harus dipenuhi sebelum atau paling lama 1 tahun pertama setelah menduduki jabatan struktural.

Berdasarkan dasar peraturan diatas, pejabat struktural masih belum mengikuti pelatihan yang telah dipersyaratkan, terdapat kesenjangan pelatihan yang telah dipersyaratkan.

Pelatihan adalah suatu aktivitas untuk meningkatkan kemampuan karyawan dengan mengalokasikan anggaran sebagai investasi. Hal yang searah dirumuskan bahwa pelatihan pada intinya adalah sebuah proses belajar. Oleh sebab itu pelatihan didefinisikan sebagai suatu proses mengajarkan ketrampilan yang dibutuhkan karyawan untuk melakukan pekerjaannya.

Pada hasil penelitian dapat dilihat pada tabel 5.3 menunjukkan bahwa terdapat beberapa jenis pelatihan yang pernah diikuti oleh pejabat. Dibagi menjadi diklat PIM, diklat fungsional dan diklat teknis. Diklat fungsional dilaksanakan untuk mencapai persyaratan kompetensi yang sesuai dengan jenis dan jenjang jabatan fungsional masing-masing, untuk menjalankan fungsi-fungsi manajemen. Diklat fungsional yang diikuti sudah sesuai dengan tugas pokok dan fungsinya. Sedangkan untuk diklat teknis pejabat struktural masih belum mengikuti pelatihan.

Disetiap unit kerja, dalam sebuah organisasi terdapat uraian rinci mengenai tugas pokok dan fungsi (tupoksi), meliputi seluruh kompetensi, baik teknis maupun teknis fungsional. Tupoksi ini seharusnya disosialisasikan dan dipahami oleh seluruh unit kerjanya. Berdasarkan tupoksi ini pula setiap petugas melaksanakan pekerjaannya sehari-hari. Namun ada juga hal-hal yang tidak terdapat di dalam tupoksi, akan tetapi besar pengaruhnya terhadap keberhasilan pencapaian tujuan organisasi.

Kompetensi pejabat dalam menjalankan tugas pokok dan fungsi masih rendah, masih dapat ditingkatkan kompetensinya menjadi lebih baik lagi melalui pelatihan.

.Kepuasan kerja dalam pekerjaan adalah kepuasan kerja yang dinikmati dalam pekerjaan dengan memperoleh pujian hasil kerja, penempatan, perlakuan, peralatan, dan suasana lingkungan kerja yang baik. Karyawan yang lebih suka menikmati kepuasan kerja dalam pekerjaan akan lebih mengutamakan pekerjaannya dari pada balas jasa walaupun balas jasa itu penting.

Hasil pengukuran IKK merupakan gambaran bagaimana kemampuan $\mathrm{RS}$ dalam mengelola SDM sebagai aset dan 
investasi intelektual sebagai ujung tombak pelayanan di RS.

\section{Analisis Organisasi}

Analisis organisasi adalah untuk melakukan analisis terhadap situasi manajerial organisasi. Sisi mana dari organisasi yang bermasalah, apakah organisasi atau unit kerja organisasi, dalam rangka meningkatkan kinerjanya membutuhkan pelatihan.

Dalam hal ini analisis organisasi pada training need assesment merupakan salah satu tahapan analisis yang dilakukan untuk menentukan kebutuhan pelatihan pada organisasi.

Pada penelitian ini analisis organisasi bertujuan mengidentifikasi jenjang jabatan, sistem pengembangan karir dan analisis kebutuhan pelatihan di RSUD dr. R. Soedarsono. Hal ini dilakukan untuk melihat kesesuaian kebutuhan pelatihan pada tiap individu dengan kebutuhan organisasi dan hasil organisasi juga digunakan untuk menentukan prioritas terhadap kebutuhan pelatihan yang akan dibutuhkan.

Pengembangan karir sangat penting bagi suatu organisasi, karena karir merupakan kebutuhan yang harus terus dikembangkan dalam diri seseorang karyawan sehingga mampu memotivasi pegawai untuk meningkatkan kinerjanya. Pengembangan karir adalah kegiatan- kegiatan pengembangan diri yang ditempuh oleh seseorang untuk mewujudkan rencana karir pribadinya.

Berdasarkan penelitian ini, dilihat dari kepuasan karyawan terhadap pengembangan karir masih rendah yaitu 49,2\%. Dilihat dari hasil IKK, rendahnya pengembangan karir kemungkinan disebabkan karena kompetensi pejabat struktural dalam melaksanakan tugas pokok fungsi rendah.

Peningkatan kompetensi kompetensi dapat dilakukan salah satunya dengan dilaksanakannya pelatihan. Dari hasil penelitian tentang kebutuhan pelatihan di dapat bahwa pelatihan yang diikuti tidak sesuai dengan standar sehingga kompetensi pejabat masih rendah.

\section{Kesimpulan Dan Saran}

\section{Kesimpulan}

Berdasarkan pembahasan yang telah dilakukan terhadap analisis kebutuhan pelatihan dan sistem pengembangan karier untuk pejabat struktural di RSUD dr. R Soedarsono dapat disimpulkan sebagai berikut :

1. Sistem pengembangan karier dilihat dari hasil IKK masih rendah. Banyak pejabat struktural yang belum mengikuti diklat sebagai prasyarat dalam jenjang karier seseorang. Hal ini akan menimbulkan IKK menjadi rendah, yang kemungkinan 
menyebabkan kinerja seseorang akan menurun. Hal yang demikian ini agar menjadi perhatian pihak manejemn untuk mengalokasikan perencanaan dalam menunjang kegiatan karier pejabat struktural.

2. Analisa kebutuhan pelatihan pejabat struktural berdasarkan training need assesment dengan analisa organisasi dan analisa individu masih kurang memadai. Sedangkan perlu diketahui, bahwa diklat pejabat struktural dimaksudkan adalah untuk peningkatan kompetensi tugas sehingga dalam perencanaan tahunan telah terprogramkan dengan baik. Untuk itu agar ditindak lanjuti dengan menugaskan pejabat struktural mengikuti diklat yang telah direncanakan.

\section{Saran}

\section{Bagi RSUD dr. R. Soedarsono}

a. Pihak manajemen rumah sakit dr. $\mathrm{R}$ Soedarsono dalam hal ini bagian umum dan kepegawaian membuat usulan pada pihak direktur untuk menugaskan pejabat struktural yang menduduki jabatan eselon III maupun eselon IV yang belum mengikuti diklat PIM untuk ditugaskan mengikuti diklat yang dimaksud.

b. Melakukan koordinasi dengan BKD Kota Pasuruan untuk melakukan identifikasi pejabat struktural terutama di RSUD dr. R Soedarsono selaku salah satu SKPD Kota Pasuruan agar segera diikutkan yang belum mengikuti diklat PIM.

c. Agar dilakukan suatu perencanaan yang kongkrit dan terstruktur oleh pihak rumah sakit terutama bidang diklat dan pengembangan mengenai pelatihan - pelatihan yang diperlukan terkait dengan peningkatan kompetensi tugas bagi pejabat struktural terutama kaitannya dengan masalah manajemen rumah sakit.

2. Bagi STIKES Yayasan RS Dr. Soetomo Surabaya

a Diharapkan dalam mata kuliah SDM ada pokok bahasan mengenai analisis kebutuhan pelatihan, dikarenakan organisasi rumah sakit membutuhkan. Peneliti kesulitan dalam melakukan analisis kebutuhan pelatihan.

3. Bagi Peneliti Selanjutnya

a Melakukan penelitian lebih mendalam mengenai hubungan indek kepuasan karyawan rendah dengan kompetensi yang rendah. 


\section{DAFTAR PUSTAKA}

Arikunto, Suharsimi. 2010. Manajemen

Penelitian. Rineka Cipta. Jakarta

Barbazette J. 2006. Training Needs Assesment, Methods, Tools and Technique. $\quad$ http://blog.uinmalang.ac.id/bangilham/barbazett e-jean-2006-training-needsassesment-methods-tools-andtechniques

Hanik, Ummu. 2016. Gambaran Pelayanan Penunjang Medis Dan Non Medis Di RSUD $d r . \quad R$. Soedarsono Kota Pasuruan. Surabaya.

Hasibuan, M. 2006. Manajemen Sumber Daya Manusia. Bumi Aksara. Jakarta

Jackson, S.E., Schuler R. S., dan Werner S. 2010. Pengelolaan Sumber Daya Manusia. Salemba Empat. Jakarta

Kamil, Mustofa. 2010 Model Pendidikan dan Pelatihan (konsep dan aplikasi). Bandung: Alfabeta

Kasmir. 2016. Manajemen Sumber Daya Manusia Teori Dan Praktik. Cetakan kesatu. Rajawali Pers. Jakarta

Munir. 2004. Pengkajian Kebutuhan Pelatihan. Cara Praktis Mengkaji Kebutuhan Pelatihan. Bapelkes. Jakarta

Notoarmodjo, $\quad$ Soekidjo. 2009. Pengembangan Sumber Daya Manusia. Jakarta PT.Rhineka Cipta

Notoatmodjo, Soekidjo. 2012. Metodologi Penelitian Kesehatan. Rineka Cipta. Jakarta

Nukman, I. 2010. Training Design Management. http://blog.uinmalang.ac.id/bangilham/tujuanpelaksanaan-pelatihan/

Peraturan Menteri Kesehatan Republik Indonesia Nomormor 971 Tahun 2009

Standar Kompetensi Pejabat Struktural Kesehatan. 5 November 2009. Jakarta
Peraturan Pemerintah Republik Indonesia Nomormor 101 Tahun 2000.

Pendidikan dan Pelatihan Jabatan

Pegawai Negeri Sipil. 10 November 2000. Jakarta

Putri, Ema Nomorvita Ristya. 2016. Gambaran Kegiatan Bidang Pengembangan dan Pengaduan Di RSUD dr. R. Soedarsono Kota Pasuruan. Surabaya.

Risfianty, Andina Erika. 2016. Gambaran Umum Kegiatan Sub Bagian Umum Dan Kepegawaian Di RSUD Dr. R. Soedarsono Kota Pasuruan. Surabaya.

Rusdiana,Basri. 2015. Manajemen Pendidikan dan Pelatihan. Cetakan kesatu. CV Pustaka Setia. Bandung

Sandjaya, Ovie Prischilia. 2016. Kajian Manajemen Bidang Keperawatan RSUD $d r . \quad R$. Soedarsono Kota Pasuruan. Surabaya.

Sinambela. 2012. Kinerja Pegawai Teori Pengukuran dan Implikasi. Edisi pertama. Graha Ilmu. Yogjakarta

Suryabrata. 2011. Metodologi Penelitian. Cetakan ke-22. Rajawali Pers. Jakarta

Syakur, Dyena Yulianti. 2016. Gambaran Bidang Perencanaan Dan Evaluasi RSUD dr. R. Soedarsono Kota Pasuruan. Surabaya.

Undang Undang Republik Indonesia Nomor 5 Tahun 2014 Aparatur Sipil Negara. 15 Januari 2014. Jakarta

Undang Undang Republik Indonesia Nomor 44 Tahun 2009 Rumah Sakit. 28 Oktober 2009

Wati, Tri Agustina. 2016. Gambaran Pelayanan Medis Dan Rujukan Di RSUD dr. R. Soedarsono Kota Pasuruan. Surabaya. 